\title{
Got Support? The Impact of Supportive Work Practices on the Perceptions, Motivation, and Behavior of Customer- Contact Employees
}

Cornell Hospitality Quarterly 54(2) I6I-173

(C) The Author(s) 2012

Reprints and permission:

sagepub.com/journalsPermissions.nav DOI: I0.1 I77//9389655/2454595

http://cqx.sagepub.com

@SAGE

\author{
John W. Michel ${ }^{1,2}$, Michael J. Kavanagh ${ }^{3}$, and J. Bruce Tracey ${ }^{4}$
}

\begin{abstract}
While scholars know a great deal about the operational challenges faced by customer-contact employees in the hospitality industry, there is much to be learned about the factors associated with the work context that influences employee motivation, performance, and retention. In this study, the authors examined the nature and impact of perceptions about an organization's customer service climate on ratings of self-efficacy, customer service job performance, and intentions to leave among employees in customer-contact positions. Results demonstrated that employees' perceptions about the climate for service quality were significantly related to motivation, supervisor ratings of service job performance, and selfrated intentions to leave. The results offer insights regarding the role of service climate perceptions and the means for effectively managing customer-contact staff and generating higher levels of retention.
\end{abstract}

\section{Keywords}

service climate, motivation, performance, retention

Numerous factors in the work environment may influence the extent to which employees in customer-contact positions are motivated to perform their roles effectively and remain committed to the organization. In a recent study of the service and hospitality firms included on Fortune magazine's list of "best companies to work for," Hinkin and Tracey (2010) found that an employee-focused environment that puts a premium on service quality plays a central role in distinguishing the firms on this list. Given the critical role of customer-contact employees in maintaining a highquality hospitality environment, it is important to understand the nature and role of employee perceptions about the work environment that may influence their attitudes, motivation, and performance regarding customer service.

Such perceptions are commonly referred to as service climate perceptions. In general, service climate refers to employee perceptions regarding the extent to which service quality behaviors are rewarded, supported, and expected by an organization (Schneider and White 2004). Two primary approaches have been taken to examine the role and impact of service climate perceptions. The first approach focuses on the collective impact of perceptions about the work context, typically characterized as organizational service climate perceptions. Researchers who have utilized this approach have examined the impact of aggregate-level service climate perceptions on various firm- or business-level measures of performance as well as individual-level outcomes such as job attitudes, motivation, and job performance (e.g., Borucki and Burke 1999; Schneider and White 2004; Way, Sturman, and Raab 2010). The findings have shown consistently positive relationships between an organization's service climate and such outcomes as customer satisfaction with service quality.

The second approach to understanding the influence of perceptions about the work context in service firms focuses on the impact of individual-level or psychological service climate perceptions. James (1982) argued that climate perceptions are best conceptualized at the psychological level since these are perceptions of individual employees. In support of this contention, research has demonstrated a significant relationship between psychological climate perceptions for service and such important outcomes as employee affect (Tsai 2001), job satisfaction (Carless 2004), job

\footnotetext{
'Loyola University Maryland, Baltimore, MD, USA

${ }^{2}$ Towson University, Towson, MD, USA

${ }^{3}$ University at Albany, Albany, NY, USA

${ }^{4}$ Cornell University, Ithaca, NY, USA

Corresponding Author:

John W. Michel, Sellinger School of Business \& Management, Loyola University Maryland, 450I N. Charles Street, Baltimore, MD 2I2।0, USA Email: jwmichel@loyola.edu
} 
performance (Brown and Leigh 1996), and customer loyalty and satisfaction (Johnson 1996).

Positive service climate perceptions are important for customer-contact employees because they represent the organization's image and brand to their customers (Schneider and White 2004). The provision of good service by customer-contact employees helps to ensure that customers' service expectations are met. Moreover, inconsistent service delivery due to factors such as high employee turnover among frontline staff may compromise service quality (Tracey and Hinkin 2008). While research has substantiated the relationship between psychological service climate perceptions and service performance (Borucki and Burke 1999; Brown and Leigh 1996), it is not clear how such climate perceptions affect employees' motivation to engage in behaviors aimed at providing high-quality service to customers.

Moreover, little is known about the influence of psychological service climate perceptions on intentions to leave among customer-contact employees. Because turnover is an especially vexing concern in the hospitality industry (Tracey and Hinkin 2008), it is important to understand the factors that may ameliorate this problem (Griffeth, Hom, and Gaertner 2000). Furthermore, most of the service climate literature has examined the direct effects of climate on individual outcomes. It is likely that the relationships between an individual's perceptions about the service climate and customer service job performance are mediated by motivational factors. Therefore, the purpose of this study is to examine the relationships among a psychological climate to support customer service, motivation, customer service job performance, and intentions to leave among customercontact employees.

We begin by discussing previous research on psychological climate in service and hospitality contexts. Then, we present the results from a study that examined the relationships between individual climate perceptions among customer-contact employees and a number of outcome variables that are critical to maintaining a high-quality service environment. Finally, we discuss the implications of our findings and present some prescriptive guidelines that may enhance efforts to cultivate a more effective, customercentric workplace.

\section{Service Climate}

Psychological climate refers to the meanings that people ascribe to various aspects of their work environment. While these perceptions can focus on the work environment in general, they can also be focused on specific aspects of the work environment (e.g., customer service). For example, Schneider and his colleagues have demonstrated that perceptions of service climate are significantly related to customer perceptions of service quality (Schneider, White, and
Paul 1998). Building on Schneider's research, Burke, Borucki, and Hurley (1992) developed a psychological service climate model that included two primary dimensions: (1) concern for employees and (2) concern for customers. This concern-based model stems from employee perceptions about a wide array of HR policies and practices that promote effective customer service performance and morale among customer-contact employees.

Burke, Borucki, and Hurley's model has been shown to relate directly to individual sales performance and indirectly to unit-level sales performance through individual sales performance (Borucki and Burke 1999). While the Burke, Borucki, and Hurley model provides valuable insight into the importance of psychological service climate perceptions, additional research is needed to determine the impact of such perceptions on various attitudes, motivation, and performance of customer-contact employees within the hospitality industry. For example, Brown and Leigh (1996) demonstrated that employee involvement mediated the relationship between psychological climate perceptions and job performance. It is likely that psychological service climate perceptions and customer service job performance are mediated by other motivational factors. Furthermore, given the prevalence of turnover among employees in the hospitality industry, consideration should be given to retentionrelated attitudes, particularly an individual's intention to leave the firm.

\section{A More Refined Model}

Building on the work of Borucki and Burke (1999) and Tracey and Tews (2005), we contend that a supportive service climate comprises three main dimensions: human resource (HR) support, management support, and job support. It is important to note that our supportive service climate construct focuses primarily on the importance of support in service contexts. In fact, Schneider, White, and Paul (1998, 151) suggested that "a climate for service rests on a foundation of fundamental support in the way of resources, training, managerial practices, and the assistance to perform effectively." Support is important because it suggests to employees that the organization values their contribution and cares about their well-being, which makes them feel more committed and satisfied, less stressed, and more motivated to perform well (Rhoades and Eisenberger 2002). As such, we define supportive service climate as employees' perceptions that their ability to provide customers with quality service is supported by the HR practices utilized by the organization, how employees are managed, and the way in which employees' jobs are designed.

As previously noted, climate perceptions are shaped by the policies, practices, and procedures that direct employee behavior at work, including HR practices used by the 
organization, the behaviors exhibited by managers, and the ways in which jobs are designed (Bowen and Ostroff 2004). Accordingly, we argue that when these three workplace characteristics emphasize support for providing good customer service, employees will perceive that they are supported, rewarded, and expected to provide good service. Consistent with previous psychological climate research (James 1982), we argue that the supportive service climate reflects a single higher-order dimension because each of the subdimensions focuses on the support given to employees for providing good service.

HR support for service quality. The first dimension, HR support for service quality, represents aspects of the organizational system (Tracey and Tews 2005) and is defined as the extent to which employees perceive that the organization's HR policies and programs demonstrate an emphasis on supporting its employees in providing high-quality customer service. HR support reflects employee-centered HR practices, such as service-related training programs, systematic performance appraisals for assessing good performance, and competitive compensation systems for rewarding good performance and focused on improving service employees' job performance and intentions to remain with the organization (Cheng-Hua, Shyh-Jer, and Shih-Chien 2009; Nishii, Lepak, and Schneider 2008). These HR practices suggest to employees that the organization will ensure they have the skills, resources, and motivation needed to adapt to various customer demands and provide effective customer service (Kusluvan et al. 2010). HR support is similar to two aspects from Burke, Borucki, and Hurley's (1992) framework: monetary reward orientation and means emphasis.

Management support for service quality. Management support for service quality represents a major part of the organization's social support system (Tracey and Tews 2005). This dimension is defined as the extent to which employees perceive that managers both encourage and reinforce the delivery of high-quality customer service and provide support to ensure the customers' and employees' needs are met. As such, it reflects the extent to which managers emphasize service quality (Susskind, Kacmar, and Borchgrevink 2007). By setting service-related goals, providing recognition and rewards to employees for providing good service, and removing obstacles that prevent employees from effectively serving customers, managers send clear signals to employees that managers will give them the support necessary to provide good customer service (Clark, Hartline, and Jones 2009; Hinkin and Schriesheim 2004). Management support is similar to three aspects from Burke, Borucki, and Hurley's framework: nonmonetary reward orientation, goal emphasis, and management support.

Job support for service quality. Job support for service quality represents work-related and technical system factors (Tracey and Tews 2005). This dimension is defined as the extent to which employees perceive that jobs are designed to promote high-quality customer service by providing the tools, equipment, and staff necessary to support employees in the provision of good customer service. When organizations design jobs in a way that helps employees serve customers, employees perceive that the organization wants to make it possible for them to provide good customer service. According to both the service-profit chain and service climate frameworks, the manner in which the job is designed and the extent to which customer-contact employees have the necessary resources can have a substantial impact on an employee's capacity for delivering high-quality customer service (Heskett, Sasser, and Schlesinger 1997; Schneider, White, and Paul 1998). Job support is similar to two aspects from Burke, Borucki, and Hurley's framework, HR-related obstacles and merchandise-related obstacles, except that we are considering job support practices that facilitate service, rather than the obstacles that impair service quality.

\section{Supportive Service Climate and Customer Service Performance}

Customer service performance includes job behaviors that service employees perform to drive customers' perceptions of service quality and satisfaction (Ryan and Ployhart 2003). These behaviors are directed at customers with the intention of benefiting or helping the customer, and as a result they represent a form of prosocial organizational behavior comprising both in-role and extrarole forms of behavior (George 1991).

Research suggests that employees tend to perform better when they perceive that the organization demonstrates concern through the provision of various forms of work-related support. For example, Borucki and Burke (1999) demonstrated that a concern for employees was related to unitlevel service performance. Similarly, researchers have shown that related constructs such as perceived organizational support (POS; Bettencourt, Gwinner, and Meuter 2001), equipment and supply support (Schneider and White 2004), and high-commitment HR practices (Nishii, Lepak, and Schneider 2008) are related to service performance. By utilizing supportive HR practices, such as service-related training and performance incentives for providing good service, organizations can provide employees with the skills and resources necessary for providing high-quality service (Liao and Chuang 2004). Similarly, when supportive managers set service-related goals, provide recognition to employees when they provide good service, help employees work together, and remove obstacles that prevent them from providing good service, they send clear signals regarding the importance of high-quality service (Schneider, White, and Paul 1998). Finally, designing jobs that ensure employees have the necessary tools, resources, and staff to handle customer demands helps employees deliver high-quality 
service (Heskett, Sasser, and Schlesinger 1997). These practices suggest to employees that they have the support necessary to provide good customer service; therefore, we hypothesize the following relationship:

Hypothesis 1: Supportive service climate is positively related to service performance.

\section{Supportive Service Climate and Intentions to Leave}

Given that turnover is an important concern and that intentions to leave have been shown to be related to actual turnover, researchers often focus on intentions to leave (Fishbein and Ajzen 1975). An employee who reports greater leave intentions is in fact more likely to leave, and measures of intentions to leave have been empirically related to actual turnover (Griffeth, Hom, and Gaertner 2000). Because customer-contact employees represent the organization's image and brand to their customers, high turnover among these employees substantially increases costs and compromises service quality (Tracey and Hinkin 2008). Such turnover may ultimately have a negative impact on customer satisfaction and loyalty (Batt 2002).

While little evidence demonstrating the relationship between psychological climate and intentions to leave exists, researchers have shown a negative relationship between similar constructs and turnover. For example, Shaw et al. (1998) found that high-commitment HR practices were negatively associated with voluntary turnover. Similarly, Ng and Sorensen (2008) demonstrated that when managers provide recognition to employees, motivate employees to work together, and remove obstacles preventing effective performance, employees feel more obligated to stay with the company. Furthermore, providing the necessary tools and resources to employees enables them to respond effectively to customer demands, but also creates a more flexible, multifunctional internal workforce that can adapt quickly to the constantly shifting competitive landscape. These practices suggest to employees that the organization values their contribution and wants them to succeed; therefore, we hypothesize,

Hypothesis 2: Supportive service climate is negatively related to intentions to leave.

\section{The Mediating Role of Self-Efficacy Beliefs}

Service environments that emphasize HR, management, and job support for service quality should promote employee self-efficacy regarding customer service performance (Maurer, Pierce, and Shore 2002). Self-efficacy is a person's belief about whether he or she can successfully perform a specific task (Bandura 1986). According to Gist and
Mitchell (1992), self-efficacy is an important motivational construct because it influences (1) goal level and commitment, (2) choice of activity, and (3) interpretation of feedback. Bandura has suggested that self-efficacy is predicted by positive emotional support, models of success with which people identify, and experience mastering a task. Employees' perceived capabilities to effectively perform their jobs, their sense of self-worth, their confidence, and their belief that their work is important and meaningful can be enhanced through the use of organizational practices such as the provision of developmental training, financial reinforcements, high performance expectations and feedback, and the resources necessary to perform their jobs (Liao et al. 2009). Furthermore, self-efficacy has been shown to improve the personal mastery or "can-do" attitude of service employees (Liao and Chuang 2007) motivating them to work harder, display more effort, and perform better in demanding situations with customers (Ahearne, Mathieu, and Rapp 2005). Therefore, we hypothesize the following relationship:

Hypothesis 3: Self-efficacy mediates the supportive service climate and service performance relationship.

Research has also demonstrated a negative relationship between self-efficacy and intentions to leave (Martin, Jones, and Callan 2005). People with higher self-efficacy experience less self-doubt and undertake new challenges at work (Wood and Bandura 1989). As stated previously, the support from HR practices, managerial behaviors, and effective job design will help employees develop a sense of self-worth and confidence in their ability to perform their job. Employees should have less self-doubt about their job performance and consequently will be less likely to want to leave the organization. Therefore, we hypothesize the following relationship:

Hypothesis 4: Self-efficacy mediates the supportive service climate and intentions to leave relationship.

The hypothesized relationships tested in this study are depicted in Exhibit 1.

\section{Method \\ Organizational Setting}

The sponsor for our study was a company that owns and operates 119 grocery stores in six states in the northeastern United States. While grocery stores may not represent a traditional hospitality context, they are quite similar to hotels and restaurants in several respects (cf. Hinkin and Tracey 2010). In particular, grocery store employees have direct and significant interactions with customers, engage 


\section{Exhibit 1:}

Proposed model of outcomes of supportive service climate

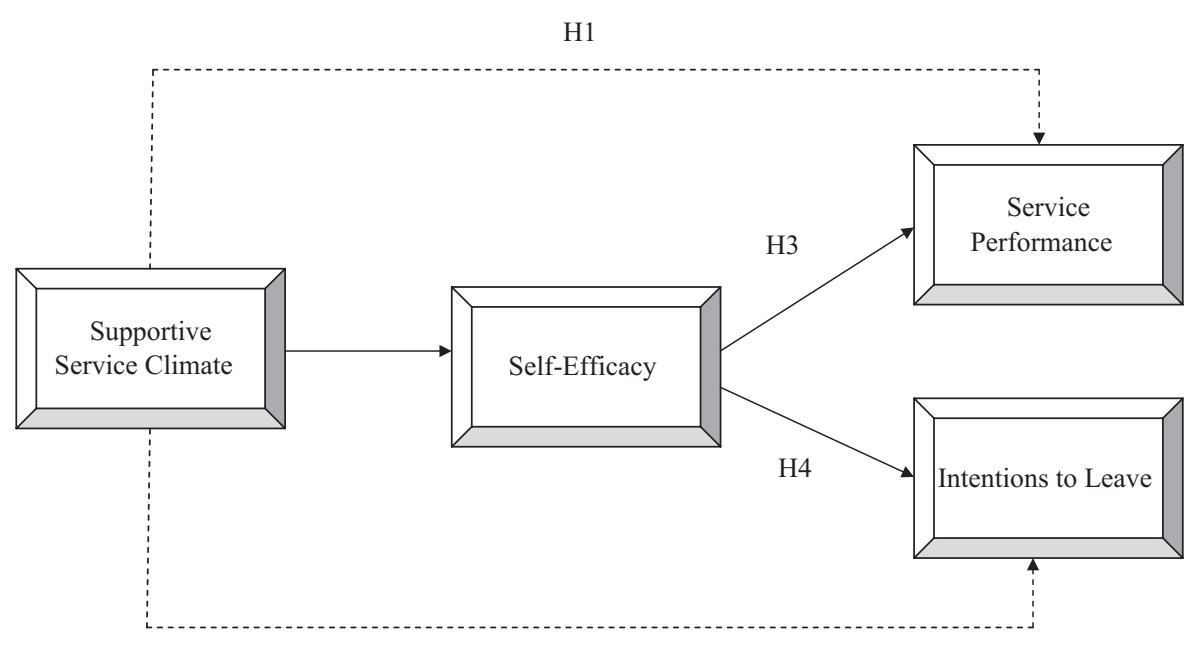

$\mathrm{H} 2$

in shift work, work in jobs characterized by low complexity and high repetition (Tracey, Sturman, and Tews 2007), are paid around the minimum wage, and are given minimal training. Moreover, as with hospitality organizations, turnover is generally high in grocery stores (Hinkin and Tracey 2010).

For this study, we were granted access to six stores with multiple departments, including general grocery, front end, meat, seafood, produce, floral, general merchandise, and bakery. The average number of supervisors in each store was twelve, and the average number of employees per store ranged from one hundred for small stores to four hundred for large stores.

\section{Participants and Procedure}

Employees. Using a stratified sampling procedure we selected every third employee listed on the schedule sorted by department, gender, and shift within each store. If a selected employee was not working on the day the data were collected or did not want to participate in the study, the next participant on the list was selected. For departments with five or fewer employees, all employees were selected for participation. Employees voluntarily completed the survey during their regularly scheduled work hours in break rooms at each store. The respondents were given both oral and written assurance that their responses would be kept confidential and that only group data would be reported to the organization. Surveys were distributed and collected by the authors in sealed envelopes to encourage candid responses. Participants provided their employee identification number on the front of the survey so that we could match their responses to their supervisors' ratings of job performance. Of participants, 96 percent $(n=158)$ returned fully completed questionnaires. The high response rate can be attributed to the support that managers gave to allow employees time to complete the survey during their shift. The participants' average age was thirty-three years, 49 percent were female, and most had at least a high school degree. The participants had been with the company for an average of eight years. There were no significant differences between the employee participants in the six stores in terms of age, gender, education level, or tenure.

Supervisors. Supervisors were given time away from work to complete performance rating forms for their subordinates who had returned questionnaires. Obtaining service performance ratings from supervisors in this way meant that some of the relationships would be tested using data from two independent sources, thus minimizing concerns of common method bias (Podsakoff et al. 2003). All supervisors $(n=45)$ of the 158 participants completed the performance ratings for their employees. The average age of supervisor participants was thirty-six, 47 percent were female, and 48 percent had some college experience. The supervisors had been with the organization an average of fourteen years and had an average of eleven years managerial experience. There were no significant differences between the supervisors from the six stores in terms of age, gender, education level, or tenure.

Matched sample. It was possible to match all 150 employee and supervisor surveys, making the final response rate for the matched sample 95 percent. No differences between the matched and unmatched surveys were found for any of the variables of interest. 


\section{Measures}

Supportive service climate. We developed the supportive service climate questionnaire using scale development procedures suggested by Hinkin (1998) and others. Twentyone items were chosen from the extant literature to reflect the three constructs and adapted to reflect support for service quality. Survey items reflected the three first-order factors, namely, HR support, management support, and job support, according to what happens in their organization and work unit. Responses in this and other sections were made on 7-point Likert-type scales, ranging from 1 (strongly disagree) to 7 (strongly agree).

The HR support dimension included six adapted items from Tracey and Tews (2005) and one item from Lytle, Hom, and Mokwa (1998). A sample item for HR support is, "There are rewards and incentives for providing high quality service to customers." The management support dimension was measured using five items adapted from Schneider et al. (2000), one item adapted from Schneider, White, and Paul (1998), and one item adapted from Tracey and Tews (2005). A sample item for management support is, "My manager sets definite quality standards of good customer service." The job support dimension was measured using seven items adapted from Schneider, White, and Paul (1998). A sample item for job support is, "We have sufficient staff in my work unit to deliver high-quality service to customers."

The fit of a higher-order supportive service climate model, in which the three first-order factors were fit to a second-order factor, was compared to a single-factor model with Mplus 6.0 (Muthén and Muthén 2007) using the sample covariance matrix as input and a maximum likelihood solution. Three item parcels were created as indicators of each latent construct in the model by randomly assigning the items to parcels, which allowed us to maintain an adequate sample size to parameter ratio (Little et al. 2002). ${ }^{1}$ The overall chi-square test of the higher-order model was significant, $\chi^{2}(24, N=158)=53.21, p<.01$; however, the individual fit indexes provided support for the proposed model - the comparative fit index (CFI) was .97, the root mean square error of approximation (RMSEA) was .09, and the standardized root mean square residual (SRMR) was .04 (Hu and Bentler 1999). Despite the high correlations among the first-order factors $(r=.81$ to $r=.86)$, the single-factor model did not fit the data well, $\chi^{2}(27, N=158)=127.38$, $p<.001, \mathrm{CFI}=.89$, RMSEA $=.15$, and SRMR $=.06$, and was a worse fit $\left(\chi_{\text {Difference (3) }}^{2}=74.17, p<.001\right)$ than the proposed model. The supportive service climate model's composite reliability was .87 .

Service self-efficacy beliefs. Employee self-efficacy was measured using a reduced eight-item version of the selfefficacy scale from Phillips and Gully (1997). These items were adapted to reflect employees' perceptions of their self-efficacy for providing high-quality service to customers. An example item is, "I feel confident in my ability to effectively provide high quality service to customers." Cronbach's alpha for this scale was .81

Intentions to leave. Employee intentions to leave were measured with the six-item Staying or Leaving Index developed by Bluedorn (1982). The six items formed one turnover intention scale; however, to minimize response bias, the two sets of items were located in two different sections of the survey, as recommended by Bluedorn. Placed in the beginning of the survey were three items asking participants to rate their chances of working with the organization three, six, and twelve months from now. The other three items, which asked participants to rate their chances of leaving the organization three, six, and twelve months from now, were placed at the end of the survey. Participants rated these six items on a 7-point scale ranging from 1 (very unlikely) to 7 (very likely). Cronbach's alpha was .93.

Control variables. Control variables in the regression analysis included demographic variables such as gender, age, highest level of education. We also controlled for work shift because the organization's management explained that the shift a person works is determined by his or her organizational tenure and job performance, and the most desirable shift is the day shift. We also controlled for organizational tenure because we felt that those who had been with the organization longer remain employed because they are better performers and thus would have fewer intentions of leaving because they have more invested into the organization.

Customer service job performance. Supervisors were asked to rate the customer service performance of each participating employee in the previous six months based on the frequency with which they displayed behaviors on a twelveitem multidimensional customer-centered behavior (CCB) measure, which has been found to have good psychometric qualities (Michel, Tews, and Kavanagh 2010). The measure consists of one second-order dimension and three first order dimensions of customer service behavior - customer assurance behaviors (four items; $\alpha=.92$ ), customer responsiveness behaviors (four items; $\alpha=.90$ ), and customer recommendation behaviors (four items; $\alpha=.88$ ). Example items include "Acknowledges customers' presence promptly" and "Offers substitutes for services or products not currently available." These behaviors were rated on a scale ranging from 1 (the employee has engaged in the behavior 0-44 percent of the time) to 7 (the employee has engaged in the behavior 95-100 percent of the time). The CCB's composite reliability was .92 .

\section{Analyses}

Prior to assessing the hypothesized relationships, it was important to determine whether supportive service 
Exhibit 2:

Descriptive Statistics and Correlations among Study Variables

\begin{tabular}{|c|c|c|c|c|c|c|c|c|c|c|c|}
\hline & $M$ & $S D$ & I & 2 & 3 & 4 & 5 & 6 & 7 & 8 & 9 \\
\hline I. Shift & 1.22 & 0.42 & - & & & & & & & & \\
\hline 2. Gender & 1.49 & 0.50 & $-.16 *$ & - & & & & & & & \\
\hline 3.Age & 33.28 & 14.36 & $-.23 * *$ & .03 & - & & & & & & \\
\hline 4. Education & 2.47 & 1.03 & .02 & -.15 & .00 & - & & & & & \\
\hline 5. Organizational tenure & 101.02 & 112.05 & $-.22^{* *}$ & .02 & $.58^{* *}$ & .02 & - & & & & \\
\hline 6. Service climate & 4.91 & I.2I & -.14 & .15 & .03 & $-.17^{*}$ & -.10 & - & & & \\
\hline 7. Self-efficacy & 6.05 & 1.04 & -.15 & $.19 *$ & .03 & .13 & -.03 & $.29 * *$ & - & & \\
\hline 8. Intentions to leave & 2.33 & 1.67 & $.25^{* *}$ & -.20 & $-.36 * *$ & .12 & $-.23^{* *}$ & $-.38 * *$ & $-.26 * *$ & - & \\
\hline 9. Service performance & 5.24 & 1.19 & $-.17 *$ & .03 & .03 & -.09 & .11 & $.23 * *$ & $.16^{*}$ & $-.22 * *$ & - \\
\hline
\end{tabular}

Note: $N=150$. Means and standard deviations are reported on the basis of a 7-point scale. Means and standard deviations for time employed in the organization are represented in months. Service performance and supportive service climate represent multidimensional constructs.

$*_{p}<.05 . * * p<.01$.

climate was best reflected at the individual or unit level of analysis prior to testing the hypotheses (Borucki and Burke 1999). ${ }^{2}$ Three estimates, ICC(1), ICC(2), and $r_{\text {wg(j) }}$, were calculated to assess the statistical justification for aggregating these data. The ICC(1) indicates the amount of variance explained between units compared to total variance. The ICC(2) is an assessment of reliability of the group means. The $F$ test associated with these analyses indicates whether the individual-level responses differ significantly by groups. In addition, the $r_{\text {wo(j) }}$ statistic was computed to provide an estimate of interrater agreement within each department (James 1982).

There was no meaningful between-group variance for the supportive service climate construct. The $F$ and intraclass correlation values for supportive service climate, $F(46,111)=1.42, p=n s, \operatorname{ICC}(1)=.11, \operatorname{ICC}(2)=.29$, were well below the values typically considered acceptable in organizational research (Bliese 2000). The median $r_{\text {wg(j) }}$ for supportive service climate was .52, which is below the .70 cutoff discussed by James (1982), indicating low agreement among employees within each department. As such, these analyses do not support aggregating the supportive service climate construct to the department level.

\section{Results}

Examination of the statistical analysis presented in Exhibit 2 suggests that supportive service climate was significantly related to service performance $(r=.23, p<.01)$ and intentions to leave $(r=-.38, p<.01)$, demonstrating support for hypotheses 1 and 2 . To test the mediated relationships, we estimated the model presented in Figure 1 using Mplus 6.0 (Muthén and Muthén 2007) with the covariance matrix as input and a maximum likelihood solution. In the structural model, supportive service climate was the exogenous variable and selfefficacy, service performance, and intentions to leave were endogenous variables (see Exhibit 3). Self-efficacy was presented as a mediator of the relationships between supportive service climate and both customer service performance and intentions to leave. We assessed the fit of the model using (1) the global chi-square test of model fit, (2) model fit statistics such as CFI, RMSEA, and SRMR, and (3) the significance of each path in the model.

Overall, the hypothesized model produced a reasonable fit to the data, $\chi^{2}(703, N=150)=1119.17, p<.001, \mathrm{CFI}=.91$, RMSEA $=.06$, and SRMR $=.09$. As depicted in Exhibit 3, all of the hypothesized path coefficients were statistically significant, thereby providing additional support for the model. To determine whether the hypothesized model is the best approximation to the data, two alternative models were tested. Alternative model 1 assessed whether the relationship between supportive service climate and service performance was partially mediated by self-efficacy, and alternative model 2 assessed whether the relationship between supportive service climate and intentions to leave was partially mediated by self-efficacy. ${ }^{3}$ While the fit statistics for both alternative models were within the conventional values, some of the paths became nonsignificant with the inclusions of the partially mediated paths. As such, the hypothesized model provided the best fit to the data.

Although not hypothesized, we found a significant relationship (see Exhibit 2) between intentions to leave and customer service job performance $(r=-.22, p<.01)$. This relationship may suggest that customer-contact employees who had greater success serving customers were ultimately happier because of their positive interactions with customers and more likely to stay in their jobs than were employees who had less success serving customers. ${ }^{4}$

\section{Discussion}

One of the key findings from this study was the significant relationship between supportive service climate and supervisor ratings of customer service job performance 


\section{Exhibit 3:}

Model of outcomes of supportive service climate

$16^{*}$

$(.08)$

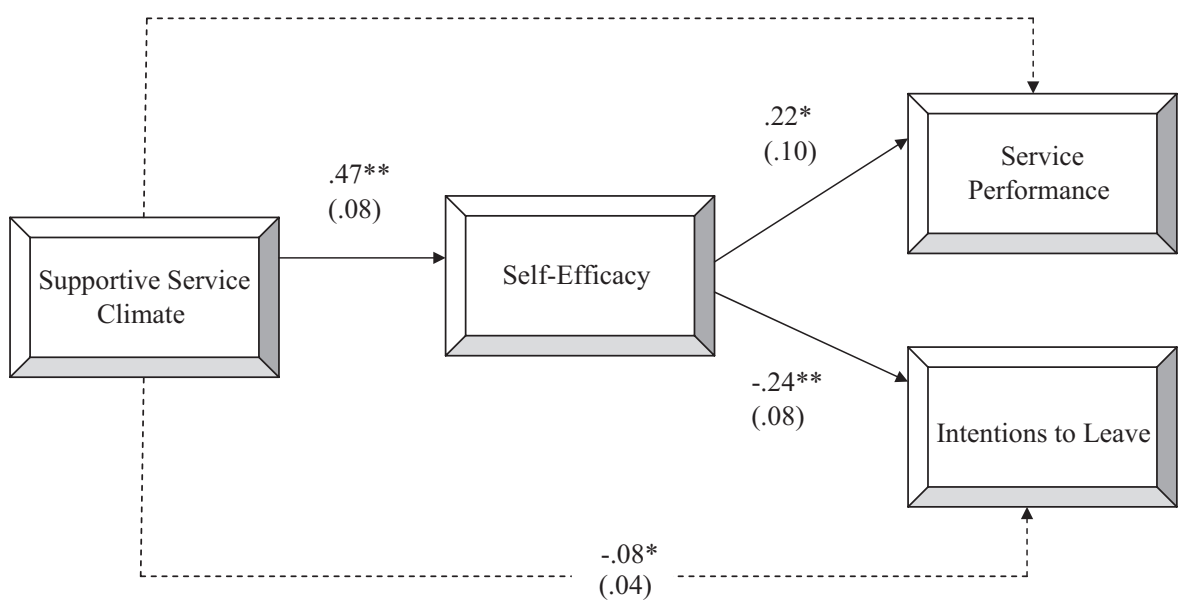

Note: The standard errors for the path coefficients appear in parentheses; dashed lines reflect the mediated effects.

$* p<.05$. **p $<.01$.

(Way, Sturman, and Raab 2010). This finding demonstrates that an individual's perception regarding support for customer service comes from a variety of work characteristics, and this support appears to be an important factor in driving customer-contact employee service performance. For example, one of the ways to enhance customer-contact employee service performance is to establish employee-centered HR programs, such as ensuring that rewards and incentives are tied to the delivery of high-quality customer service and providing training to develop employee skills necessary for providing highquality customer service. In addition, it appears that supervisors play an important role in creating a high-quality service context that supports effective customer service behaviors among customer-contact employees - a finding that is consistent with previous research (Susskind, Kacmar, and Borchgrevink 2007). Finally, our results suggest that the design of jobs can affect employee customer service performance, particularly by ensuring that employees have the right supplies and equipment and that sufficient staff members are available during each shift to assist in the provision of high-quality service to customers. Thus, this study provides needed insights regarding the impact of employee service perceptions on service-specific job performance.

The results also showed that supportive service climate was significantly related to employees' intentions to leave the organization. While previous research has demonstrated the link between HR practices, manager behaviors, and job design with turnover, to our knowledge this is the first study to examine the relationship between psychological climate perceptions of support and retention-specific outcomes. The results also showed that supportive service climate was positively related to self-efficacy and that self-efficacy mediated the supportive service climate-service performance and supportive service climate-intentions to leave relationships. In other words, providing support to employees gives them the confidence to perform their jobs better and the motivation to stay with the organization. Taken together, it appears that supportive service climate has a fairly broad and ubiquitous impact on customer-contact employees. Moreover, these findings provide a more comprehensive conceptual explanation of the nature and impact of individual climate perceptions with respect to support for creating and sustaining high levels of service quality.

One avenue of future research is to examine the ways in which supportive service climate may be related to other climate and support constructs. For example, given that supportive service climate is a psychological climate construct reflecting work-related support, future research should determine its relationship with constructs such as POS. That concept is conceptually distinct from supportive service climate in that the latter reflects descriptive cognitive appraisals of specific aspects of their work environment that may influence service job performance, while POS reflects employees' general affective reactions regarding the organization's commitment to their personal wellbeing. As such, it may be worthwhile to investigate the extent to which supportive service climate may be an antecedent of POS since employees' cognitive appraisals of 
support may influence their feelings regarding the degree to which the organization cares about their well-being. Similarly, Schneider, White, and Paul (1998) demonstrated that supportive practices are an important determinant of global service climate perceptions. As such, future research should investigate the relationship between the supportive service climate and global service climate perceptions.

A second area of future research concerns the level of analysis at which supportive service climate should be conceptualized. Given that supportive service climate is an assessment of psychological climate, it is plausible to aggregate this construct to the unit level of analysis (Borucki and Burke 1999). However, in our study, assessments of the interrater agreement and reliability indicated that service climate was best conceptualized at the individual level of analysis. These estimates can be attributed to the number of groups included in the sample $(n=45)$ and the average number of participants (3.33) within each group (Bliese 1998). Another reason for these low estimates may be our use of the individual as the referent within the survey questions, as opposed to the group. Chan (1998) suggests that with the referent-shift consensus model, individuals' rate the group's perception of climate rather than only their own. Future research should use this latter perspective to ascertain the unit-level relationship between supportive service climate and service quality and customer satisfaction and the cross-level relationship between supportive service climate and service performance and intentions to leave.

\section{Limitations}

The results of this study should be interpreted within the context of three limitations. First, although we provided tests of the direct and indirect relationships hypothesized in this study, the data are cross-sectional. Therefore, the direction of causality between the study's variables cannot be ascertained by our results. It may be, for example, that effective customer service performance affects the amount and kind of support for service quality provided by the organization. It could also be that support for service quality influences employees' customer service job performance. Finally, the causal relationship between these two variables may be bidirectional. Thus, longitudinal research should investigate these possible causal linkages.

A second limitation is that supportive service climate, self-efficacy, and intentions to leave were all collected from the same source, potentially leading to common method bias $(\mathrm{CMB})$ and thereby providing possible alternative explications for the observed relationships between variables. Concerns of CMB were assuaged using statistical and procedural remedies recommended by Podsakoff et al. (2003). Using a statistical approach, two CFAs were conducted to demonstrate the discriminate validity of these factors. The model including the higher-order supportive service climate dimension, self-efficacy dimension, and turnover intention dimension fit the data, $\chi^{2}(83, N=158)=$ $110.53, p<.05, \mathrm{CFI}=.98, \mathrm{RMSEA}=.05$, and $\mathrm{SRMR}=.07$, better than a single-factor model, $\chi^{2}(90, N=158)=847.90$, $p<.001, \mathrm{CFI}=.55$, RMSEA $=.23$, and SRMR $=.14$, providing evidence for the discriminant validity of the three constructs.

Three procedural remedies were also used in the measurement of the variables as suggested by Podsakoff et al. (2003) to reduce CMB. First, we reduced evaluation apprehension by providing respondents with verbal and written assurances of confidentiality and that there were no right or wrong answers. Second, we obtained attitude and perception measures from employees and service performance ratings from managers. Third, the response format used to assess intentions to leave was operationally distinct from those used to measure the other self-report constructs. Finally, recent literature suggests that CMB is not as pervasive as once assumed and has taken on the characteristics of an "urban legend" (Spector 2006). Spector argues that if $\mathrm{CMB}$ were so prevalent, we would expect a baseline of correlations among all variables measured with the same selfreport survey. This baseline did not appear in the results of this study. The correlations among the self-reported variables depicted in Table 1 ranged from -.38 to .29. This difference represents a significant magnitude, rather than a baseline, among these variables.

A third limitation of this study was that data were collected from grocery store employees rather than hospitalityspecific employees (typically, those in hotels and restaurants). Hinkin and Tracey (2010) used grocery stores in a sample of more traditional hospitality organizations as part of a study in which they determined the HR practices used by organizations listed on the Fortune 100 best companies to work for list. In support of the inclusion of grocery stores in their study, Hinkin and Tracey noted that grocery stores are similar to traditional hospitality organizations in various ways such as heavy customer interactions, extensive operating hours, and jobs characterized by low complexity, repetition, minimal training, and high turnover (Hinkin and Tracey 2010). With this said, future research should be conducted with a sample of traditional hospitality organizations to ensure that our findings can be generalized.

\section{Managerial Implications}

This research provides a number of practical implications for hospitality organizations. In particular, our findings suggest that shaping perceptions of support is especially important in motivating customer-contact employees to provide consistent, high-quality service and remain committed to the organization. In addition, our study provides a framework for diagnosing a firm's service climate as well as formalizing employee competencies through job descriptions, 
staffing procedures, training programs, performance management systems, management practices, and redesigning jobs. Thus, organizations can utilize the supportive service climate measure to learn more about their HR policies, practices, and procedures that may influence employee perceptions, attitudes, and behaviors associated with customer service.

Our results suggest that one way to shape supportive service climate perceptions in employees is through the implementation of employee-centered HR practices that help employees deliver quality service to customers, such as job design, staffing systems, training programs, and compensation plans (Nishii, Lepak, and Schneider 2008). As noted above, Hinkin and Tracey (2010) identified a wide array of HR practices that have been implemented by various service and hospitality companies that are included on Fortune's list of most admired companies to work for. Some of these practices included the use of flexible scheduling initiatives such as job sharing and compressed work weeks and innovative staffing practices such as promoting an employee-centric brand by publicizing awards received by the company and providing referral awards to employees. In addition, increasing the rigor of staffing procedures and emphasizing the importance of customer service are necessary for promoting a high-quality, service-focused environment. For example, Publix Supermarkets requires job candidates to take a twenty-five-minute online test to assess their customer service knowledge and skills (Hinkin and Tracey 2010). Doing so ensures that employees have the skills needed to deal with customer demands, thereby increasing the chance of success in the job. Other practices include continuous developmental opportunities for all employees and utilizing a clearly defined performance evaluation system that accounts for customer service processes and outcomes. For example, Harrah's entertainment provides quarterly bonuses to employees based on the quality of service provided to customers (Tracey and Way 2011). This sends a message to employees that quality customer service is important for the success of Harrah's and for its employees.

Another way of shaping the supportive service climate perceptions of employees is to ensure that managers set service-related goals, provide recognition and rewards to employees for good service, and remove obstacles that prevent employees from effectively serving customers. The behavior of a service employee's immediate supervisor may be the most salient factor that can affect employees' perceptions of the supervisor's support for them (Testa and Ehrhart 2005). Supervisors can be trained to provide nonmonetary recognition to service employees through behavioral modeling programs (Taylor, Russ-Eft, and Chan 2005). Similarly, managers can be trained to effectively set goals related to service quality, remove obstacles that prevent employees from achieving desired quality standards, and provide feedback and recognition to employees to build their self-efficacy and motivate them to provide quality service and to remain with the organization. Similarly, managers could be more flexible in scheduling employees and designing the work in support of their employees. This is especially important in hospitality because these organizations typically operate around the clock and have a nontraditional workforce, such as parents with child care issues and younger workers concerned with balancing work, school, and life issues (Hinkin and Tracey 2010). For example, Marriott offers employees the opportunity to work compressed workweeks (i.e., four 10-hour days or three 12-hour days), and Stew Lenard's "Moms Program" allows working mothers to schedule their work around child care or other child activities (Hinkin and Tracey 2010). This suggests to employees that their managers care about employees' well-being, thereby motivating them to reciprocate this favorable treatment by providing quality customer service (Susskind, Kacmar, and Borchgrevink 2003).

\section{Conclusion}

Creating and sustaining a competitive advantage in the hospitality industry requires an unwavering focus on customer service. The results from our study demonstrate the importance and impact of cultivating a supportive work climate that promotes effective service performance and motivation among customer-contact employees. By implementing service-focused HR practices, ensuring that managers place a priority on service quality, and designing jobs that provide the necessary resources and support to deliver exceptional customer service, employees will be more engaged and committed to their work and deliver on the firm's customer service promises. Over time, hospitality organizations will realize a stronger competitive position and achieve superior levels of efficiency, quality, and financial performance.

\section{Authors' Note}

This article is based on the first author's dissertation.

\section{Acknowledgments}

We thank Gary Yukl and Raymond Van Ness for their assistance with this research.

\section{Declaration of Conflicting Interests}

The author(s) declared no potential conflicts of interest with respect to the research, authorship, and/or publication of this article.

\section{Funding}

The author(s) disclosed receipt of the following financial support for the research, authorship, and/or publication of this article: The Faculty Development and Research Committee of Towson University 
and the Summer Research Grant Program in the College of Business \& Economics at Towson University provided valuable financial support for the preparation of this article.

\section{Notes}

1. Items were assigned to parcels within factor. The items from the HR support scale were used to create three parcels for the HR support factor, items from the management support scale were used to create three parcels for the management support factor, and items from the job support scale were used to create three item parcels for the job support factor.

2. It is important to note that climate perceptions emanate from an individual's cognitive appraisals of the environment. As a result, it is most appropriate to measure these perceptions at the individual level of analysis and treat the construct as an organizational climate only when the perceptions can be meaningfully aggregated to the unit or organizational level (James 1982).

3. Results from the alternative model tests can be obtained from the first author.

4. We would like to thank one of the anonymous reviewers for suggesting this point.

\section{References}

Ahearne, M., J. E. Mathieu, and A. Rapp. 2005. “To Empower or Not to Empower Your Sales Force? An Empirical Examination of the Influence of Leadership Empowerment Behavior on Customer Satisfaction and Performance." Journal of Applied Psychology 90:945-955.

Bandura, A. 1986. Social Foundations of Thought and Action. Englewood Cliffs, NJ: Prentice Hall.

Batt, R. 2002. "Managing Customer Services: Human Resource Practices, Quit Rates, and Sales Growth." Academy of Management Journal 45:587-97.

Bettencourt, L. A., K. P. Gwinner, and M. L. Meuter. 2001. "A Comparison of Attitude, Personality, and Knowledge Predictors of Service-Oriented Organizational Citizenship Behaviors." Journal of Applied Psychology 86:29-41.

Bliese, P. D. 1998. "Group Size, ICC Values, and Group-Level Correlations: A Simulation." Organizational Research Methods 1:355-73.

Bliese, P. D. 2000. "Within-group agreement, non-independence, and reliability." In Multilevel Theory, Research, and Methods in Organizations, edited by K. J. Klein and S. W. J. Kozlowski, pp. 349-81. San Francisco: Jossey-Bass.

Bluedorn, A. C. 1982. "A Unified Model of Turnover from Organizations." Human Relations 35:135-53.

Borucki, C. C., and M. J. Burke. 1999. "An Examination of Service-Related Antecedents to Retail Store Performance." Journal of Organizational Behavior 20:943-62.

Bowen, D. E., and C. Ostroff. 2004. "Understanding HRMFirm Performance Linkages: The Role of the "Strength" of the HRM System." Academy of Management Review 29:203-21.
Brown, S. P., and T. W. Leigh. 1996. "A New Look at Psychological Climate and Its Relationship to Job Involvement, Effort and Performance." Journal of Applied Psychology 81:358-68.

Burke, M. J., C. C. Borucki, and A. E. Hurley. 1992. "Reconceptualizing Psychological Climate in a Retail Service Environment: A Multiple Stakeholder Perspective." Journal of Applied Psychology 77:717-29.

Carless, S. A. 2004. "Does Psychological Empowerment Mediate the Relationship between Psychological Climate and Job Satisfaction?" Journal of Business and Psychology 18:405-25.

Chan, D. 1998. "Functional Relations among Constructs in the Same Content Domain at Different Levels of Analysis: A Typology of Composition Models." Journal of Applied Psychology 83:234-46.

Cheng-Hua, T., C. Shyh-Jer, and F. Shih-Chien. 2009. "Employment Modes, High-Performance Work Practices, and Organizational Performance in the Hospitality Industry." Cornell Hospitality Quarterly 50:413-31.

Clark, R. A., M. D. Hartline, and K. C. Jones. 2009. "The Effects of Leadership Style on Hotel Employees' Commitment to Service Quality." Cornell Hospitality Quarterly 50:209-31.

Fishbein, M., and I. Ajzen. 1975. Belief, Attitudes, Intention, and Behavior. Reading, MA: Addison-Wesley.

George, J. M. 1991. "State or Trait: Effects of Positive Mood on Prosocial Behavior at Work." Journal of Applied Psychology 76:299-307.

Gist, M. E., and T. R. Mitchell. 1992. "Self-Efficacy: A Theoretical Analysis of Its Determinants and Malleability." Academy of Management Review 17:183-211.

Griffeth, R. W., P. W. Hom, and S. Gaertner. 2000. "A Metaanalysis of Antecedents and Correlates of Employee Turnover: Update, Moderator Tests, and Research Implications for the Next Millennium." Journal of Management 26:463-88.

Heskett, J. L., W. E. Sasser, Jr., and L. A. Schlesinger. 1997. The Service Profit Chain. New York: Free Press.

Hinkin, T. R. 1998. "A Brief Tutorial on the Development of Measures for Use in Survey Questionnaires." Organizational Research Methods 1:104-21.

Hinkin, T. R., and C. A. Schriesheim. 2004. "If You Don't Hear from Me You Know You Are Doing Fine: The Effects of Management Nonresponse to Employee Performance." Cornell Hotel and Restaurant Administration Quarterly 45:362-72.

Hinkin, T. R., and J. B. Tracey. 2010. "What Makes It So Great? An Analysis of Human Resources Practices among Fortune's Best Companies to Work For." Cornell Quarterly 51:158-70.

Hu, L., and P. M. Bentler. 1999. "Cutoff Criteria for Fit Indexes in Covariance Structure Analysis: Conventional Criteria versus New Alternatives.” Structural Equation Modeling 6:1-55.

James, L. R. 1982. "Aggregation Bias in Estimates of Perceptual Agreement." Journal of Applied Psychology 67:219-29.

Johnson, J. W. 1996. "Linking Employee Perceptions of Service Climate to Customer Satisfaction." Personnel Psychology 49:831-51. 
Kusluvan, S., Z. Kusluvan, I. Ilhan, and L. Buyruk. 2010. "The Human Dimension: A Review of Human Resources Management Issues in the Tourism and Hospitality Industry." Cornell Hospitality Quarterly 51:171-214.

Liao, H., and A. Chuang. 2004. "A Multilevel Investigation of Factors Influencing Employee Service Performance and Customer Outcomes." Academy of Management Journal 47:41-58.

Liao, H., and A. Chuang. 2007. "Transforming Service Employees and Climate: A Multilevel, Multisource Examination of Transformational Leadership in Building Long-Term Service Relationships.” Journal of Applied Psychology 92:1006-19.

Liao, H., K. Toya, D. P. Lepak, and Y. Hong. 2009. "Do They See Eye to Eye? Management and Employee Perceptions of High-Performance Work Systems and Influence Processes on Service Quality." Journal of Applied Psychology 94:371-91.

Little, T. D., W. A. Cunningham, G. Shahar, and K. F. Widaman. 2002. "To Parcel or Not to Parcel: Exploring the Question, Weighing the Merits." Structural Equation Modeling 9:151-73.

Lytle, R. S., P. W. Hom, and M. P. Mokwa. 1998. "SERV*OR: A Managerial Measure of Organizational Service-Orientation." Journal of Retailing 74:455-89.

Martin, A. J., E. S. Jones, and V. J. Callan. 2005. "The Role of Psychological Climate in Facilitating Employee Adjustment during Organizational Change." European Journal of Work and Organizational Psychology 14:263-89.

Maurer, T. J., H. R. Pierce, and L. M. Shore. 2002. "Perceived Beneficiary of Employee Development Activity: A ThreeDimensional Social Exchange Model." Academy of Management Review 27:432-44.

Michel, J. W., M. J. Tews, and M. J. Kavanagh. 2010. "Development and Validation of the Customer-Centered Behavior Measure." Working paper, Towson University.

Muthén, L. K., and B. O. Muthén. 2007. Mplus Users Guide. 5th ed. Los Angeles: Muthén and Muthén.

Ng, T. W. H., and K. L. Sorensen. 2008. "Toward a Further Understanding of the Relationships between Perceptions of Support and Work Attitudes: A Meta-Analysis." Group \& Organization Management 33:243-68.

Nishii, L. H., D. P. Lepak, and B. Schneider. 2008. "Employee Attributions of the 'Why' of HR Practices: Their Effects on Employee Attitudes and Behaviors, and Customer Satisfaction." Personnel Psychology 61:503-45.

Phillips, J. M., and S. M. Gully. 1997. "Role of Goal Orientation, Ability, Need for Achievement, and Locus of Control in the Self-Efficacy and Goal-Setting Process." Journal of Applied Psychology 82:792-802.

Podsakoff, P. M., S. B. MacKenzie, J. Lee, and N. P. Podsakoff. 2003. "Common Method Biases in Behavioral Research: A Critical Review of the Literature and Recommended Remedies." Journal of Applied Psychology 88:879-903.

Rhoades, L., and Eisenberger, R. 2002. "Perceived organizational support: A review of the literature." Journal of Applied Psychology, 87:698-714.
Ryan, A. M., and R. E. Ployhart. 2003. "Customer Service Behavior." In Handbook of Psychology: Industrial and Organizational Psychology, vol. 12, edited by W. C. Borman, D. R. Ilgen, and R. J. Klimoski, Vol. 12, pp. 377-97. Hoboken, NJ: John Wiley.

Schneider, B., D. E. Bowen, M. G. Ehrhart, and K. M. Holcombe. 2000. "The Climate for Service: Evolution of a Construct." In Handbook of Organizational Culture \& Climate, edited by W. C. Borman, D. R. Ilgen, and R. J. Klimoski, pp. 21-36. Thousand Oaks, CA: Sage.

Schneider, B., and S. S. White. 2004. Service Quality: Research Perspectives. Thousand Oaks, CA: Sage.

Schneider, B., S. S. White, and M. C. Paul. 1998. "Linking Service Climate and Customer Perceptions of Service Quality: Test of a Causal Model." Journal of Applied Psychology 83:150-63.

Shaw, J. D., J. E. Delery, G. D. Jenkins, Jr., and N. Gupta. 1998. "An Organization-Level Analysis of Voluntary and Involuntary Turnover." Academy of Management Journal 41:511-25.

Spector, P. E. 2006. "Method Variance in Organizational Research: Truth or Urban Legend?" Organizational Research Methods 9:221-32.

Susskind, A. M., K. M. Kacmar, and C. P. Borchgrevink. 2003. "Customer Service Providers' Attitudes Relating to Customer Service and Customer Satisfaction in the Customer-Server Exchange." Journal of Applied Psychology 88:179-87.

Susskind, A. M., K. M. Kacmar, and C. P. Borchgrevink. 2007. "How Organizational Standards and Coworker Support Improve Restaurant Service." Cornell Hospitality Quarterly 48:370-79.

Taylor, P. J., D. F. Russ-Eft, and D. W. L. Chan. 2005. "A MetaAnalytic Review of Behavior Modeling Training." Journal of Applied Psychology 90:692-709.

Testa, M. R., and M. G. Ehrhart. 2005. "Service Leader Interaction Behaviors: Comparing Employee and Manager Perspectives." Group \& Organization Management 30:456-86.

Tracey, J. B., and T. R. Hinkin. 2008. "Contextual Factors and Cost Profiles Associated with Employee Turnover." Cornell Hospitality Quarterly 49:12-27.

Tracey, J. B., M. C. Sturman, and M. J. Tews. 2007. “Ability versus Personality: Factors That Predict Employee Job Performance." Cornell Hospitality Quarterly 48:313-22.

Tracey, J. B., and M. J. Tews. 2005. "Construct Validity of a General Training Climate Scale." Organizational Research Methods 8:353-74.

Tracey, J. B., and S. A. Way. 2011. "Making the Most of Your Human Capital." In The Cornell School of Hotel Administration on Hospitality: Cutting Edge Thinking and Practice, edited by M. C. Sturman, J. C. Corgel, and R. Verma, 444-54. Hoboken, NJ: John Wiley.

Tsai, W. 2001. "Determinants and Consequences of Employee Displayed Positive Emotions." Journal of Management 27:497-512.

Way, S. A., M. C. Sturman, and C. Raab. 2010. "What Matters More? Contrasting the Effects of Job Satisfaction and Service Climate on Hotel Food and Beverage Managers' Job Performance." Cornell Hospitality Quarterly 51:379-97. 
Wood, R., and A. Bandura. 1989. "Social Cognitive Theory of Organizational Management." Academy of Management Review 14:361-84.

\section{Bios}

John W. Michel is an assistant professor of management in the Joseph A. Sellinger, S.J. School of Business \& Management at Loyola University Maryland (jwmichel@loyola.edu).
Michael J. Kavanagh is professor emeritus in the School of Business at the University at Albany, State University of New York (mickey.kavanagh@gmail.com).

J. Bruce Tracey is an associate professor in the School of Hotel Administration at Cornell University (jbt6@cornell.edu). 